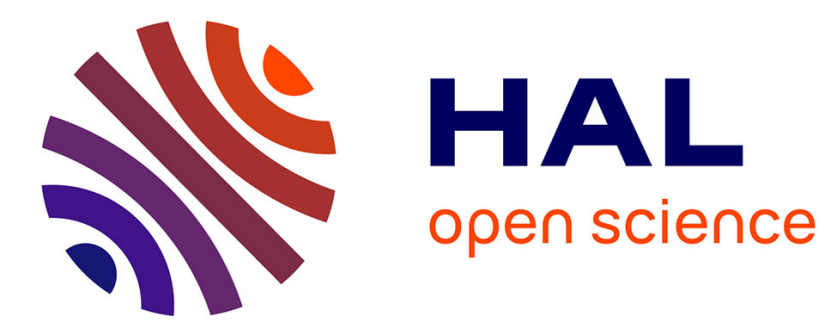

\title{
Structure engineering of filled protein microbeads to tailor release of oil droplets in gastric digestion
}

Pauline van Leusden, Gertjan J. M. den Hartog, Aalt Bast, Michiel Postema, Erik van Der Linden, Leonard Sagis

\section{To cite this version:}

Pauline van Leusden, Gertjan J. M. den Hartog, Aalt Bast, Michiel Postema, Erik van Der Linden, et al.. Structure engineering of filled protein microbeads to tailor release of oil droplets in gastric digestion. Food and Function, 2016, 7 (8), pp.3539-3547. 10.1039/c6fo00405a . hal-03192844

\section{HAL Id: hal-03192844 \\ https://hal.science/hal-03192844}

Submitted on 13 Apr 2021

HAL is a multi-disciplinary open access archive for the deposit and dissemination of scientific research documents, whether they are published or not. The documents may come from teaching and research institutions in France or abroad, or from public or private research centers.
L'archive ouverte pluridisciplinaire HAL, est destinée au dépôt et à la diffusion de documents scientifiques de niveau recherche, publiés ou non, émanant des établissements d'enseignement et de recherche français ou étrangers, des laboratoires publics ou privés. 


\section{Food \& Function}

2014 Impact Factor: 2.791

www.rsc.org/foodfunction

\section{FULL PAPER SUBMISSION}

\section{Linking the chemistry \& physics of food with health \& nutrition}

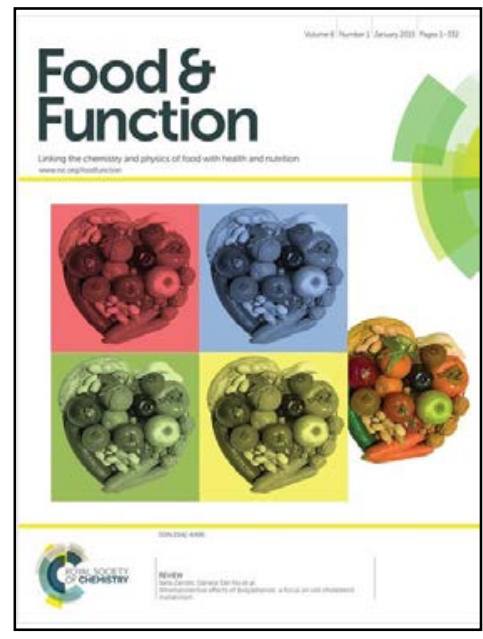

The following article has been submitted to Food \& Function for consideration as a Full Paper.

Food \& Function provides a unique venue for physicists, chemists, biochemists, nutritionists and other food scientists to publish work at the interface of the chemistry, physics and biology of food. The journal focuses on food and the functions of food in relation to health; this includes the following:

- Physical properties and structure of food

- Chemistry of food components

- Biochemical and physiological actions

- Nutritional aspects of food

Articles relating purely to food analysis will not be published in Food \& Function - these can be published in our sister journal, Analytical Methods.

Food \& Function Full Papers must describe high impact science that will be of benefit to the community and are judged according to originality, quality of scientific content and contribution to existing knowledge. Only the most significant papers (top 25\%) will be considered for acceptance.

Good quality work, however competently researched and reported, should not be recommended for publication if it does not meet the criteria with regards to highly original and immediate interest to the broad food research community.

Authors are encouraged to provide a succinct and relevant introduction to the research and to consider the use of the Electronic Supplementary Information for additional material.

Thank you for your effort in reviewing this submission. It is only through the continued service of referees that we can maintain both the high quality of the publication and the rapid response times to authors. We would greatly appreciate if you could review this paper in $\mathbf{1 4}$ days. Please let us know if that will not be possible.

Once again, we appreciate your time in serving as a reviewer. To acknowledge this, the Royal Society of Chemistry offers a $\mathbf{2 5 \%}$ discount on our books: http://pubs.rsc.org/bookshop. Please also consider submitting your next manuscript to Food \& Function.

Best wishes,

Philippa Ross

Executive Editor
Professor Kevin Croft

Editor-in-Chief 


\section{Structure engineering of filled protein microbeads to tailor}

\section{2 release of oil droplets in gastric digestion}

3

4

5

Authors: P. van Leusden ${ }^{1}$, G.J.M. den $\operatorname{Hartog}^{2}$, A. Bast ${ }^{2}$, M. Postema ${ }^{3,4}$, E. van der Linden ${ }^{1}$, L.M.C. Sagis ${ }^{1}$

1 Physics and Physical Chemistry of Foods Group, Department of Agrotechnology and Food Sciences, Wageningen University, Bornse Weilanden 9, 6708 WG Wageningen, The Netherlands

2 Department of Pharmacology and Toxicology, Maastricht University, PO Box 616, 6200 MD Maastricht, The Netherlands

3 Institute of Fundamental Technological Research, Polish Academy of Sciences, ul. Adolfa Pawińskiego 5 B, 02-106 Warszawa, Poland

4 School of Electrical and Information Engineering, Chamber of Mines Building, University of the Witwatersrand, 1 Jan Smuts Avenue, Braamfontein, Johannesburg 2050, South Africa

Oil-soluble components can be encapsulated in an $\mathrm{O} / \mathrm{W}_{1} / \mathrm{W}_{2}$ microsystem, in which they are dissolved in oil droplets dispersed in a gelled microbead $\left(\mathrm{W}_{1}\right)$, which forms a barrier between the oil droplets and continuous, aqueous continuous phase $\left(\mathrm{W}_{2}\right)$. We investigated the rate and mechanism of breakdown of protein microbeads in a simulated gastric system, and studied the 
influence of microbead protein concentration, gelling method (cold-set, slow and fast heatset), and further processing (freeze-drying), on the breakdown process. Breakdown rate decreased with increasing protein content of the beads, for the same method of production. Due to the porosity of the slowly-heated heat-set beads, breakdown occurred evenly throughout the entire bead. Cold-set microbeads of $10 \%$ protein broke down slightly slower than the heat-set microbeads of $15 \%$. The denser surface of the $10 \%$ beads slowed down the diffusion of the enzymes into the bead's interior, causing the beads to be broken down from the outside inward. All these beads broke down within one hour. Increasing the rate of temperature increase during the heating step dramatically slowed breakdown. There was no significant breakdown of rapidly heated beads within 138 minutes, even though no difference in microstructure between rapidly and slowly heated beads was visible with electron microscopy. Freeze-drying of the beads also slowed their breakdown. After 132 minutes more than half the measured particle volume of were intact beads. Freeze-drying changed the microstructure of the beads irreversibly: rehydrating the dried beads did not result in a breakdown behaviour similar to that of unprocessed beads. 


\section{Introduction}

For encapsulation systems to be effective, functional ingredients need to be protected from external influences until they are delivered to specific locations where they need to be released. The filled hydrogel bead is one of the many types of encapsulation systems that have been developed and investigated in the past decades ${ }^{1}$. This is an $\mathrm{O} / \mathrm{W}_{1} / \mathrm{W}_{2}$ system in which sensitive oil soluble components are incorporated in an oil phase $(\mathrm{O})$ dispersed within gelled microbeads $\left(\mathrm{W}_{1}\right)$, which are dispersed in a liquid phase $\left(\mathrm{W}_{2}\right)^{2}$.

Models describing the breakdown and digestion of nutrients generally lack consideration for the matrix in which the nutrients are entrapped ${ }^{3}$. Parada \& Aguilera concluded that the bioavailability of a nutrient is more important than the actual amount of nutrient ingested, and that this depends on the matrix in which the nutrient is located ${ }^{4}$. The relatively large surface area of small oil droplets promotes digestion by lipases ${ }^{5}$. Li et al. have shown that encapsulating lipids into filled hydrogel beads made of alginate retards lipid digestion ${ }^{6}$. They ascribe this retardation to presence of the matrix, which slows the diffusion of both lipase to the interface and free fatty acids away from the interface of the oil droplets. Previously we have investigated the strength of smaller, similar beads, made of WPI or alginate ${ }^{7}$. However, while alginate is not digested in the stomach, protein is extensively digested in the stomach. The rate at which the protein matrix is digested will influence the rate of lipid digestion and release of compounds that may be located in the oil phase. Digestive stability of whey protein microcapsules has been investigated previously and have proven to protect certain strains of probiotic microorganisms, such as Lactobacillus rhamnosus and Bifidobacterium breve ${ }^{8-10}$. These studies vary widely in how the protein matrixes are created (spray drying, cold-set $\mathrm{Ca}^{2+}$ gelation, cold-set acid gelation, heat-set gelation). Because both the production of the matrices 
and the microorganism that is encapsulated vary, these studies do not allow comparison between different encapsulation systems.

Recently we established that the method of production greatly affected the mechanical strength of microbeads made with the same type and concentration of polymer Both WPI or alginate beads were stronger if the gelling agent was added externally, through the continuous phase, instead of including it in the internal phase of the bead, and that this gelling method was more important to bead strength than the matrix polymer. It was concluded that the externally added gelling agent, which entered the system at the interface of the beads, created a dense 'shell' which was very resistant to the high shear and extensional forces applied on the beads during processing ${ }^{7}$. Internally gelled microbeads had a more open and porous structure and were severely damaged in conditions where externally gelled beads remained intact.

These differences in microstructure of the beads may not only affect mechanical stability of the beads, but also the rate of breakdown of the beads in the gastrointestinal tract. Guo et al. showed that protein gels with different hardness or different protein concentrations broke down differently in a simulated gastrointestinal system ${ }^{11}$. No exact description of the microstructure of the 'hard' or 'soft' macroscopic gel was given, however it was clear that pepsin had more effect on the soft gel. Luo et al. also found that heat-set WPI gels of 15 and $20 \%$ protein had different breakdown rates, with respectively $50 \%$ vs $11 \%$ of the gels broken down after 6 hours ${ }^{12}$. They also found that, at $\mathrm{pH} 3$, the breakdown was entirely caused by the presence of pepsin and not a result of the low $\mathrm{pH}$. Barbé et al. concluded that the rate of digestion of protein can be changed by applying different processes on the same mix of proteins, in their case heating and/or gelation of the protein mixes ${ }^{13}$. Microbeads produced with different methods and different gel strengths are therefore also likely to break down 
differently. The difference in gelling method and resulting microstructure would thus give opportunities for the development of different types of microencapsulation systems for release at different locations in the digestive tract.

For the rate of diffusion of a component into or out of a microbead, the porosity, size, and charge of the bead, and size and charge of the component are of great significance ${ }^{1,14}$. For filled hydrogel beads, the encapsulated components are oil soluble and are therefore generally slow or unable to diffuse out of the microbead. Lipase itself may diffuse through the bead, digesting and releasing small amounts of fatty acids, but for complete and rapid digestion to occur the matrix of the bead should be broken down. Current knowledge on how such beads break down, and which variables determine the rate of the process is still lacking.

In the gastrointestinal tract food encounters a wide range of pH's and enzymes, which digest food. The structure and material of the beads will determine how well and how long the sensitive component inside is protected. A larger size, a higher polymer concentration and higher degree of cross-linking will slow down the release of the component. The porosity may also play a role, because a finer gel with smaller pores may slow down the diffusion of the enzyme into the bead. When the rate of the enzymatic reaction is much higher than the enzyme can diffuse into the interior of the bead we call the system diffusion limited, and the system will break down from the outside in. This would be visible in a size distribution of the beads as a gradual shift to smaller bead sizes. When the enzyme diffuses into the beads much faster than the enzyme needs to break down the substrate, we call the system reaction limited. In this case the bead will be digested evenly over its entire volume, which would be visible in the size distribution as a gradual decrease of the intensity of the peak representing the average bead size, and an increase in intensity for the peak representing free oil droplets. 
114 The charge of WPI is dependent on the $\mathrm{pH}$, which in turn has an effect on the microstructure

115 of the gelled beads. At the isoelectric point (WPI: 5.1) ${ }^{15}$ the molecules will exhibit a net 116 attraction between each other. This will cause the beads to shrink, which might reduce access 117 of proteolytic enzymes. In addition, beads may aggregate into clusters, possibly reducing 118 enzyme access even further. Exposing beads to the low $\mathrm{pH}$ of the stomach however, proteins 119 become more positively charged, causing repulsion between the molecules and swelling of the 120 bead $^{3}$. This leads to bigger pores and easier access for enzymes.

Recent research has shown that digestion of proteins is affected by changing the processing of the proteins ${ }^{11-13,16}$. For the creation and development of new, protein gel-based, delivery systems, we need a better understanding of the relation between microstructure and the rate of breakdown of the delivery systems, and also the factors that are important to the rate of breakdown. The objective of this study was to investigate the impact of variations of the microstructure, created by changing the interior protein concentration and the production and processing method, on the gastric digestion rates and mechanisms of oil filled protein beads. 


\subsection{Materials}

133

134

Whey protein isolate (WPI) purity 98\% (Davisco Foods international, France), Alginate (Texturas, Barcelona, Spain), $\mathrm{CaCl}_{2} \cdot 2 \mathrm{H}_{2} \mathrm{O}$ (purity $\geq 99 \%$, Merck, Germany), ethanol absolute (purity $\geq 99.2 \%$, Merck, Germany), polyglycerol polyricinoleate (PGPR) 90 kosher (Danisco, Denmark), Medium Chain Triglycerides (MCT) (Miglyol 812 N, Sasol, Germany), DextranFITC (40 $000 \mathrm{Da}$ ), (Sigma Aldrich, Germany) were all used as received. For the simulated gastric system, $\mathrm{KCl}, \mathrm{NaCl}, \mathrm{MgCl}_{2},\left(\mathrm{NH}_{4}\right)_{2} \mathrm{CO}_{3}$ (Sigma Aldrich, USA), $\mathrm{KH}_{2} \mathrm{PO}_{4}, \mathrm{NaHCO}_{3}$ (Merck, Germany) were used. Pepsin from porcine gastric mucosa (EC.3.4.23.1, Sigma Aldrich, USA) had an activity of $3802 \mathrm{U} / \mathrm{mg}$. Solutions were made in demineralized water.

\subsection{Production of WPI heat-set beads (15\%, 20\%, $25 \%$, and rapidly heated $25 \%$ )}

A primary emulsion, which later formed the inner oil phase, was made by mixing $5 \%(\mathrm{w} / \mathrm{w})$ MCT in a 15, 20 or $25 \%(\mathrm{w} / \mathrm{w})$ protein in water solution ( $\mathrm{pH} 6.8)$ with the Ultra-Turrax (T 25, Germany) at $8000 \mathrm{rpm}$ for 2 minutes. The emulsion was then further homogenized (Delta instruments, Drachten, The Netherlands) for 4 passes at 100 bar. The primary emulsion itself was then emulsified by slowly adding $10 \%(\mathrm{v} / \mathrm{v})$ to an MCT solution containing $2.5 \%(\mathrm{w} / \mathrm{w})$ PGPR, while mixing with the Ultra-Turrax at $4200 \mathrm{rpm}$, thereby creating an O/W/O emulsion. After full addition, the double emulsion was mixed for another 4 minutes. The double emulsion was then put in a water bath of $80{ }^{\circ} \mathrm{C}$ for 20 minutes, while continuously stirring to allow the protein in the water phase to gel.

The rapidly heated $25 \%$ beads were made by slowly adding (in about 10 minutes) the double emulsion to MCT containing 2.5\% PGPR which was preheated to $80{ }^{\circ} \mathrm{C}$. The temperature of the mixture was kept above $79^{\circ} \mathrm{C}$ during the addition of the double emulsion, after which the 
155

emulsion was stirred for 20 more minutes at $80{ }^{\circ} \mathrm{C}$. Since the continuous phase is already at about $80{ }^{\circ} \mathrm{C}$ upon addition of the double emulsion droplets, these beads are produced at a much higher temperature gradient $\left(\sim 10^{6} \mathrm{~K} / \mathrm{m}\right)$, then beads produced from double emulsions prepared at room temperature, followed by heating of the entire double emulsion $\left(\sim 10^{3} \mathrm{~K} / \mathrm{m}\right)$. For both methods the beads were cooled to room temperature using tap water and stored at 4 ${ }^{\circ} \mathrm{C}$ for at least a night and until use.

\subsection{Production of $\mathrm{CaCl}_{2}$ nanocrystals}

Calcium nanocrystals were made according to the method of Paques et al. ${ }^{17}$. A volume of 5\% of a solution of 0.1 molal $\mathrm{CaCl}_{2} .2 \mathrm{H}_{2} \mathrm{O}$ in ethanol was emulsified in MCT containing $6 \%$ (w/w) PGPR, with a sonicator (Sonicator S-250A, Branson Ultrasonics, USA) for 1 minute. The emulsion was stirred and heated overnight at $60{ }^{\circ} \mathrm{C}$ without a cover, which allowed the ethanol to evaporate, giving a $5 \% \mathrm{CaCl}_{2}$ nanocrystals dispersion.

\subsection{Production of WPI externally gelled beads}

Protein aggregates were made by heating a $10 \%(\mathrm{w} / \mathrm{w})$ protein solution of $\mathrm{pH} 8$ for 30 minutes at $80{ }^{\circ} \mathrm{C}$ while stirring. After heating, the solutions were cooled with tap water and stored at $4{ }^{\circ} \mathrm{C}$. The double emulsion was prepared as for the heat-set protein beads, however instead of using a 15, 20 or $25 \%$ WPI solution the $10 \%$ WPI aggregate solution was used. After emulsification the double emulsion was gelled with calcium by adding the $\mathrm{CaCl}_{2}$ nanocrystal dispersion in a ratio of $7.23 \mathrm{~mL}$ per $10 \mathrm{~mL}$ of double emulsion and stirring it overnight. The beads were stored at $4{ }^{\circ} \mathrm{C}$ until use.

\subsection{Removal of beads from the outer oil phase}


179 Protein microbeads were removed from the oil phase by centrifuging the dispersion at $2500 \mathrm{~g}$

\subsection{Freeze-dried protein beads}

The redispersed beads were frozen with liquid nitrogen and Freeze-dried (Christ Alpha 2-4 LD plus, Martin Christ, Germany). The powder was stored in a desiccator until use.

\subsection{Surface morphology}

Surface morphology was examined by scanning electron microscopy (SEM; Magellan 400, FEI, Eindhoven, the Netherlands). The samples were adhered to coverslips, critical point dried with $\mathrm{CO}_{2}$, and then sputter coated (Leica EM SCD 500, Leica, Vienna, Austria) with a 10nm iridium layer.

\subsection{Protein and oil content}

To measure the encapsulation efficiency the beads were freeze-dried to remove all water. The protein content of the dried beads was measured by DUMAS (Flash EA 1112 Analyzer, Thermo Fisher Scientific, USA). The rest of the weight was assumed to be oil.

\subsection{Dry matter content}

Addition of the amount of beads to the simulated gastrointestinal system was based on equal amounts of beads, which was based on dry matter content. A measured volume of dispersion 
was put in an oven of $105{ }^{\circ} \mathrm{C}$ overnight. Based on the dry matter content a calculation was made (with the assumption that no oil was added or lost during the second emulsification step) to find the volume of beads. The bead dispersion was diluted to a volume fraction of 0.20. MCT is not volatile and did not noticeably evaporate during 20 hours at $105^{\circ} \mathrm{C}$.

\subsection{Simulated gastric system}

The gastrointestinal system was made as described by Minekus et al. ${ }^{18}$. We assumed the beads to be present in a liquid phase, thereby bypassing the oral phase. Simulated gastric fluid (SGF) electrolyte stock solutions were made as described. A $20 \%(\mathrm{v} / \mathrm{v})$ bead dispersions and the $\mathrm{CaCl}_{2}$ solution were added to SGF after which the $\mathrm{pH}$ was adjusted to 3 . The solution was put on an automatic stirrer at $37^{\circ} \mathrm{C}$. Then pepsin was added in the concentrations mentioned (2000 U/mL). Every 6 minutes, before and during enzyme treatment, samples were taken and bead size was measured.

\subsection{Size distribution}

The size distribution of the beads, before and during the treatment in the simulated gastrointestinal system, was measured with the Mastersizer (Malvern Mastersizer 2000, Malvern Instruments, UK) using laser diffraction. The volume percent of the beads, oil droplets, and aggregates was determined by calculating the surface area of the respective peaks in the particle size distribution curve. The results shown are an average of two measurements, the error bars show the standard deviation.

\subsection{Light microscopy}

Pictures of the rehydrating freeze-dried $25 \%$ beads were made with a light microscope (Axioskop 2 plus, Carl Zeiss, Germany) 
$230 \quad 2.13$ Diffusion of probe molecules

231 To further investigate whether the breakdown of the protein beads was diffusion or reaction 232 limited, the diffusion through the matrix was investigated using a tracer particle of similar 233 molecular weight as pepsin. Dextran-FITC (40 $000 \mathrm{Da}$ ) was added in 20mmol (similar as to 234 the pepsin concentration in the stomach) to $1 \%$ samples of the $25 \%$ heat-set, $25 \%$ rapidly 235 heated, $25 \%$ hydrated freeze-dried and $10 \%$ cold-set beads in simulated gastric fluid (SGF) at $236 \mathrm{pH}$ 3. The diffusion of the Dextran-FITC over time was examined by confocal laser scanning 237 microscopy (CSLM, Leica TCS-SP5, Leica Microsystems B.V., Rijswijk, Netherlands). 


\section{Results and discussion}

\subsection{Surface morphology (SEM)}

Protein beads were created by the various preparation methods and imaged with SEM, the results of which can be found in Figure 1. The 15, 20, 25 and rapidly heated $25 \%$ heat-set beads have an open and porous structure. The pores appear to be large enough for a pepsin molecule (34620 Da, about $10 \mathrm{~nm}$ ) to enter, which suggests that these beads should display a reaction-limited breakdown. The $10 \%$ cold-set beads have a much denser surface structure. There are still pores visible, however they are much smaller than in the heat-set beads. This might slow or completely stop the diffusion of pepsin into the beads, therefore the cold-set beads are more likely to give a diffusion limited breakdown. The actual concentration of protein in the $10 \%$ cold-set bead is however lower than for the heat-set beads, which are made from protein concentrations of $15 \%$ and above, which means that less protein needs to be broken down before the inner oil droplets are released. The freeze-dried $25 \%$ beads show a very dense surface with several large surface defects. The surface of the $25 \%$ heat-set beads is thus changed by the process of freezing and freeze-drying. The denser the surface, the more likely it is to hinder diffusion and access of pepsin. The cracks in the surface are however likely to promote bead breakdown.

\subsection{Protein content}

Table 1 shows the measured vs. the calculated protein content. The calculated protein content is the amount of protein that was put into the system. The measured protein content is the amount of protein actually measured by DUMAS. Since the sample was completely dried, we have assumed for the calculated value that the beads consist primarily of protein and oil, and have neglected any contributions from salts to the total weight. Based on the DUMAS results, 
it can be seen that for all samples the measured protein content is lower than the expected protein content. This reduction of protein content means that either extra oil was emulsified into the protein phase during the double emulsification step, or that protein was lost from the matrix during washing. It is probable that during the washing steps, protein that was not tightly bound in the matrix was washed out. The $10 \%$ beads which were gelled with the coldset method lost the most protein, about $9 \%$ while the other samples lost on average about $2 \%$. The amount of aggregation that occurs between proteins is dependent on the protein concentration ${ }^{19}$. The cold-set gel of only $10 \%$ protein is therefore expected to have the highest concentration of non-aggregated protein present. These non-aggregated proteins can diffuse out of the bead during washing. Other authors also saw loss of protein from their system ${ }^{8,20,21}$. Though it is impossible to say if oil was lost during emulsification and gelation, based on the DUMAS results it can be concluded that a large amount of the oil originally added to the interior of the beads is still present.

\subsection{Bead breakdown}

The graphs of Figure 2 show the size distribution of components present during the breakdown of the beads in SGF. Enzyme was added separately after 6 minutes, to see if the beads react to the SGF itself.

During the breakdown of the beads we determined the size distribution of the beads as a function of time. Figure 3 shows an example of the size distribution graphs over time. The solid line is the size distribution of the oil droplets in the $25 \%$ WPI solution, after the first emulsification, but before the second emulsification and gelation step. At $\mathrm{t}=0$ (min) a sample was taken just before the addition of pepsin. The size distribution shows only the beads which are about $10 \mu \mathrm{m}$ in size. During the breakdown of the beads, sometimes particles were 
detected with a size of around $100 \mu \mathrm{m}$. These large particles were few in number and were most likely aggregates of beads and/or oil droplets. These peaks always disappeared when the beads were completely broken down which suggests that flocculation was induced by the partially broken down protein. The actual content of these peaks are discussed per sample. At $\mathrm{t}=42(\min )$ the breakdown is in progress, oil droplets, beads and aggregates are present. At $\mathrm{t}=54$ (min) no further breakdown occurs and only oil droplets, which are not affected by the presence of pepsin, are present.

For the $25 \%$ beads, after the enzyme was added, the average diameter of the beads increased over 18 minutes, from about $8 \mu \mathrm{m}$ to $9 \mu \mathrm{m}$. This suggests that the enzymes diffused into the beads where they have broken bonds. Together with the low $\mathrm{pH}$ of the system, this led to swelling of the beads. After 18 minutes the bead diameter decreased, which suggests a breakdown of the beads. Single oil droplets were first detected 30 minutes after the addition of pepsin. When about $20 \%$ of the volume represented single oil droplets, and thus a significant amount of beads had broken down, the diameter of the beads $(8.9 \mu \mathrm{m})$ was still larger than the diameter of the beads before pepsin was added $(8.2 \mu \mathrm{m})$. These observations suggest a mechanism where the pepsin was able to diffuse into the bead relatively fast. Subsequently the enzyme started to break down the protein matrix throughout the entire bead, and when enough bonds had been broken the bead disintegrated into smaller pieces, releasing the oil droplets. The smaller pieces initially (at least partially) aggregated into larger clusters, and are subsequently broken down even further. Therefore for the $25 \%$ heat-set beads the breakdown mechanism is reaction limited. Within 48 minutes of the beads entering the simulated gastric system, all the internal oil droplets were released. 
The 20\% WPI beads started releasing oil droplets 12 minutes after addition of the enzyme. No significant increase in diameter was seen as for the $25 \%$ beads. However, because of their microstructure, which is similar to that of the $25 \%$ beads (as seen in the SEM images) and the lower amount of protein present, we assume that here the enzymes were also able to diffuse relatively fast throughout the bead, and the breakdown mechanism is reaction limited. After the first 12 minutes, where oil droplets were first observed, most of the beads broke down within the next 12 minutes. For the $20 \%$ beads, both the lag time before release of oil droplets and the time within which the oil droplets were completely released were significantly shorter than for the $25 \%$ heat-set beads.

The $15 \%$ heat-set beads started releasing their oil immediately after addition of pepsin which is too fast to allow any conclusions about the mechanism of breakdown. From the similarities in microstructure observed in the SEM images between the $15 \%$ beads and the 25 and $20 \%$ heat-set beads, it is reasonable to assume that the breakdown was again reaction limited. Where the $25 \%$ beads were stable for 24 minutes, and the $20 \%$ beads were stable for 12 minutes, the $15 \%$ beads were stable for less than 6 minutes. Extrapolating these observations, the $10 \%$ beads were expected to break down more quickly than the $15 \%$ beads.

However the $10 \%$ cold-set beads showed a release of individual oil droplets 12 minutes after pepsin addition. In that same time span the peak height in the volume distribution of the beads reduced by about $20 \%$ and the bead diameter was reduced from 12 to about $8 \mu \mathrm{m}$. This more gradual decrease (compared to that observed in the 15 to $25 \%$ beads) in size suggests that the beads were broken down from the outside in, and the breakdown is therefore predominantly diffusion limited, which is different from the heat-set beads. A decrease in diameter from 12 to $8 \mu \mathrm{m}$ corresponds to a decrease in volume of the beads of $70 \%$. With such an extent of 
breakdown and the fact that oil droplets were present throughout the bead, it is unlikely that oil droplets were not released during the first 12 minutes. The oil droplets may have initially been in a flocculated state and hence represented by the aggregate peak.

When comparing the extent of breakdown of the beads after 12 minutes it is visible that for the $15 \%$ heat-beads the amount of beads has decreased more than for the $10 \%$ cold-set beads, about $75 \%$ decrease versus $15 \%$. The $15 \%$ heat-set beads thus broke down faster than the $10 \%$ cold-set beads, despite the lower protein content of the $10 \%$ beads. The SEM results show that the $10 \%$ beads have a much denser surface and this denser surface may slow down the diffusion of pepsin into the interior of the beads. As a result the breakdown mechanism has shifted from reaction limited to diffusion limited.

The rapidly-heated $25 \%$ heat-set beads broke down much more slowly than the standard $25 \%$ heat-set beads. The rapidly-heated beads showed a much more significant degree of swelling of the beads in this initial phase of the breakdown (from 7.5 to $13.6 \mu \mathrm{m}$ ). After 90 minutes, the radius did not increase further, and remained stable. No significant release of oil droplets was registered in a time span of 138 minutes, which is longer than the average residence time of 2 hours in the stomach, according to Minekus et al. ${ }^{18}$. Beads which are put in SGF without pepsin did not show a significant change in radius (results not shown) so the pepsin clearly plays a role in the increase in radius. The fast temperature increase from room temperature to $80^{\circ} \mathrm{C}$, apparently resulted in a significantly different protein matrix which was much more resistant to enzymatic breakdown. This difference in matrix is however not visible in SEM analysis and there was also no significant difference in protein content of the beads. 
The difference in protein matrix that was found between the $25 \%$ heat- set and rapidly-heated $25 \%$ heat-set beads might be found in the mechanism of protein gelation. Protein gelation occurs roughly in two steps: the unfolding of the protein and the progressive aggregation of the unfolded protein until a network is formed. The rapid heating most likely did not allow for complete unfolding of the protein before aggregation occurred, resulting in a network with proteins with more native folds than a network induced by slow heating. Barbé et al. found that unheated $\beta$-lactoglobulin shows more resistance to hydrolysis in the stomach than heated $\beta$-lactoglobulin, which breaks down more easily ${ }^{13}$. Dalgalarondo et al. similarly found that $\beta$ lactoglobulin was only cleaved in ethanol concentrations higher than $20 \%$, where the presence of ethanol caused changes in the structure of $\beta$-lactoglobulin ${ }^{22}$.

Figure 4 shows the breakdown of freeze-dried, 25\% heat-set beads. The freeze-dried $25 \%$ beads broke down slower than the standard $25 \%$ heat-set beads. At the start of the measurement we observed large aggregates, which were most likely flocs of beads, which were slowly broken up by gentle stirring, both in water and after addition of SGF. The addition of pepsin increased the speed in which the flocs fell apart into separate beads. After 30 minutes most beads appeared to be separated. Their size and number was then stable for another 66 minutes before oil droplets were released. The data shows more variation here. However, on average, after an enzyme treatment of 132 minutes, longer than the average residence time of 2 hours in the stomach, about $60 \%$ of the volume still consisted of intact beads. These beads hence broke down much more slowly than the standard $25 \%$ heat-set beads.

Upon microscopic observation of the freeze-dried $25 \%$ heat-set beads during enzymatic breakdown in the simulated gastric system, a distinct line within the beads was observed, 
which moved further inward over time (Figure 5, left). This is most likely a hydration front which slowly moved into the bead. The breakdown of the beads might be slowed down by the time the bead needs to fully hydrate. In regions that are not fully hydrated, the enzyme cannot diffuse easily and thus cannot break down the matrix. To see if the removal of this hydration time would give a similar breakdown pattern as the standard $25 \%$ heat-set beads, a sample of the freeze-dried beads was left in water overnight and given the SGF and pepsin treatment the next day. Microscopic observation showed that this hydration line was not present anymore and full hydration was assumed (Figure 5, right).

The hydrated, freeze-dried beads also showed flocs at the start of the measurement, but these were smaller than those observed in the sample which was not rehydrated. After about 18 minutes (compared to 30 minutes for the freeze-dried sample) the flocs were broken down to single beads by the presence of pepsin. After 36 more minutes, 6 minutes more than for the standard 25\% heat-set beads but 36 minutes less than for the freeze-dried beads, individual oil droplets started being released. Again the data shows significant variation here, but substantial release occurs within the average time of 2 hours that food stays in the stomach.

In the detailed graph of the freeze-dried and rehydrated, freeze-dried beads, it can be seen that when oil droplets were released, the bead diameter was still as large as it was before oil droplets were released, as was also with the standard $25 \%$ beads. This means that, though the breakdown was markedly slower than the standard $25 \%$ beads, it was still a reaction limited breakdown.

Compared to the normal $25 \%$ heat-set beads, it took more time before oil droplets were released from the hydrated beads, and it took more time before all beads were broken down. 
412 Compared to the freeze-dried beads, it took less time before oil droplets were released from the hydrated beads and it took less time for the beads to break down. This was partly caused by the flocculation and dehydration, as hydrated freeze-dried beads broke down more quickly, but removal of the flocculation and dehydration did not revert the freeze-dried sample to the behaviour of the non- freeze-dried sample. The breakdown was still markedly slower. In the SEM results it can be seen that the surface morphology of the freeze-dried and non-freezedried samples was very different. Strambini and Gebellieri found that changes in secondary and tertiary structure occur in single tryptophan molecules when freezing ${ }^{23}$. Li et al. found that freeze-drying increased aggregate size of soy proteins ${ }^{24}$. The freezing and freeze-drying process thus changed the structure markedly, as also seen in the SEM images. This change slowed down the breakdown of the beads. Because both systems are reaction limited, we expect that the process of freeze-drying created protein structures within the bead, which were harder for pepsin to cut.

\subsection{Diffusion of probe molecules}

Images of the diffusion of Dextran-FITC through the beads can be found in Figure 6. The green areas in the image indicate where Dextran-FITC is present. Images A, B and C show that Dextran-FITC diffuses into and throughout the $25 \%$ heat-set, $25 \%$ rapidly heated and $25 \%$ hydrated freeze-dried beads within 1.5 minutes. For the $25 \%$ heat-set and $25 \%$ hydrated freeze-dried, and thereby by extension also $20 \%$ and $15 \%$ heat-set beads, the diffusion is therefore confirmed to be very fast and the breakdown of the beads is predominantly reaction limited. Images D show that the Dextran-FITC does not diffuse easily into the $10 \%$ cold-set bead. After 1.5 minutes, there is clearly more Dextran-FITC at the outer perimeter than in the centre of the bead. Only after 12 minutes is the Dextran-FITC homogenously distributed 
throughout the bead. The mechanism of breakdown for the $10 \%$ beads is therefore more likely to be diffusion than reaction limited.

The results of this study have been summarised in Table 2

In this study we showed that the structure of filled hydrogel beads is important for the rate and way these beads break down and release their load. The variations of release found in this study, while using the same building blocks, gives opportunities in the creation of novel targeted release systems. When a quick release of the encapsulated compound is required, a low protein concentration and a reduced heating gradient during gelation are recommended. When a delayed release in the intestinal tract is required, a high protein concentration, external gelation, an increased heating gradient during gelation and application of freezedrying should be used. In the case of slow release systems, and thus slow digestion of the proteins, one must however be aware that the release and digestion can be so slow as to reduce the nutritional availability and also that not fully digested proteins can cause allergic reactions in the intestine ${ }^{25}$. 
453

454

455

456

457

458

459

460

461

462

463

464

465

466

467

468

469

470

471

\section{Conclusions}

In this study we investigated the influence of protein concentration, method of gelation, and freeze-drying on the speed and way of breakdown of oil filled protein microbeads.

Similarly produced microbeads with a higher protein concentration break down slower. The porous nature of the heat-set beads assured that the pepsin could diffuse throughout the bead and break the entire bead down evenly, resulting in a reaction limited breakdown process. The cold-set $10 \%$ protein microbead was broken down slightly slower than the $15 \%$ heat-set beads. Because of the method of gelation, the surface of the $10 \%$ beads was much denser, which resulted in a diffusion barrier for the pepsin and resulted in a diffusion-limited breakdown of the beads. Increasing the rate of temperature increase of the heating step changed the breakdown kinetics of the $25 \%$ heat-set beads, and these beads needed more than 2 hours to break down. Both the standard 25\% and rapidly heated 25\% heat-set beads allowed diffusion of enzyme throughout the bead and no difference in surface morphology or probe diffusion was seen. When the $25 \%$ beads are freeze-dried, the rate of breakdown is greatly slowed. Flocculation and dehydration of the beads were important factors but rehydrating did not revert the breakdown kinetics of the freeze-dried beads back to that of the standard $25 \%$ beads. The freeze-drying altered the microstructure of the beads, therefore it took longer for the pepsin to break down the structure. 
References:

1. D. J. McClements, Nanoparticle-and microparticle-based delivery systems: Encapsulation, protection and release of active compounds, CRC Press, 2014.

2. D. J. McClements, Current Opinion in Colloid \& Interface Science, 2012, 17, 235245.

3. H. Singh, A. Ye and M. J. Ferrua, Current Opinion in Food Science, DOI: http://dx.doi.org/10.1016/j.cofs.2015.06.007.

4. J. Parada and J. M. Aguilera, Journal of Food Science, 2007, 72, R21-R32.

5. M. Armand, P. Borel, P. Ythier, G. Dutot, C. Melin, M. Senft, H. Lafont and D. Lairon, The Journal of Nutritional Biochemistry, 1992, 3, 333-341.

6. Y. Li, M. Hu, Y. Du, H. Xiao and D. J. McClements, Food Hydrocolloids, 2011, 25, 122-130.

7. P. van Leusden, G. den Hartog, A. Bast, M. Postema, E. van der Linden and L. Sagis, Food Hydrocolloids, 2016, 56, 318-324.

8. S. B. Doherty, V. L. Gee, R. P. Ross, C. Stanton, G. F. Fitzgerald and A. Brodkorb, Food Hydrocolloids, 2011, 25, 1604-1617.

9. A. Picot and C. Lacroix, International Dairy Journal, 2004, 14, 505-515.

10. A. A. Reid, J. C. Vuillemard, M. Britten, Y. Arcand, E. Farnworth and C. P. Champagne, Journal of Microencapsulation, 2005, 22, 603-619.

11. Q. Guo, A. Ye, M. Lad, M. Ferrua, D. Dalgleish and H. Singh, Food \& Function, 2015, 6, 756-764.

12. Q. Luo, R. M. Boom and A. E. M. Janssen, LWT - Food Science and Technology, 2015, 63, 161-168.

13. F. Barbé, O. Ménard, Y. Le Gouar, C. Buffière, M.-H. Famelart, B. Laroche, S. Le Feunteun, D. Dupont and D. Rémond, Food Chemistry, 136, 1203-1212.

14. W. R. Gombotz and S. F. Wee, Advanced Drug Delivery Reviews, 2012, 64, Supplement, 194-205.

15. C. M. Bryant and D. J. McClements, Trends in Food Science \& Technology, 1998, 9, 143-151.

16. S. B. Kim, K. S. Ki, M. A. Khan, W. S. Lee, H. J. Lee, B. S. Ahn and H. S. Kim, Journal of Dairy Science, 2007, 90, 4043-4050.

17. J. P. Paques, E. van der Linden, C. J. M. van Rijn and L. M. C. Sagis, Food Hydrocolloids, 2012, 31, 428-434.

18. M. Minekus, M. Alminger, P. Alvito, S. Ballance, T. Bohn, C. Bourlieu, F. Carrière, R. Boutrou, M. Corredig and D. Dupont, Food \& function, 2014, 5, 1113-1124.

19. A. C. Alting, R. J. Hamer, C. G. de Kruif, M. Paques and R. W. Visschers, Food Hydrocolloids, 2003, 17, 469-479.

20. P. Croguennoc, T. Nicolai, M. E. Kuil and J. G. Hollander, The Journal of Physical Chemistry B, 2001, 105, 5782-5788.

21. C. Wu, Y. Hua, Y. Chen, X. Kong and C. Zhang, Journal of Agricultural and Food Chemistry, 2015, 63, 4211-4219.

22. M. Dalgalarrondo, E. Dufour, J.-M. Chobert, C. Bertrand-Harb and T. Haertlé, International Dairy Journal, 1995, 5, 1-14.

23. G. B. Strambini and E. Gabellieri, Biophysical journal, 1996, 70, 971.

24. X. Li, Y. Li, Y. Hua, A. Qiu, C. Yang and S. Cui, Food Chemistry, 2007, 104, 14101417.

25. M. Wickham, R. Faulks and C. Mills, Mol. Nutr. Food Res., 2009, 53, 952-958. 
$520 \quad$ Figure 1

521

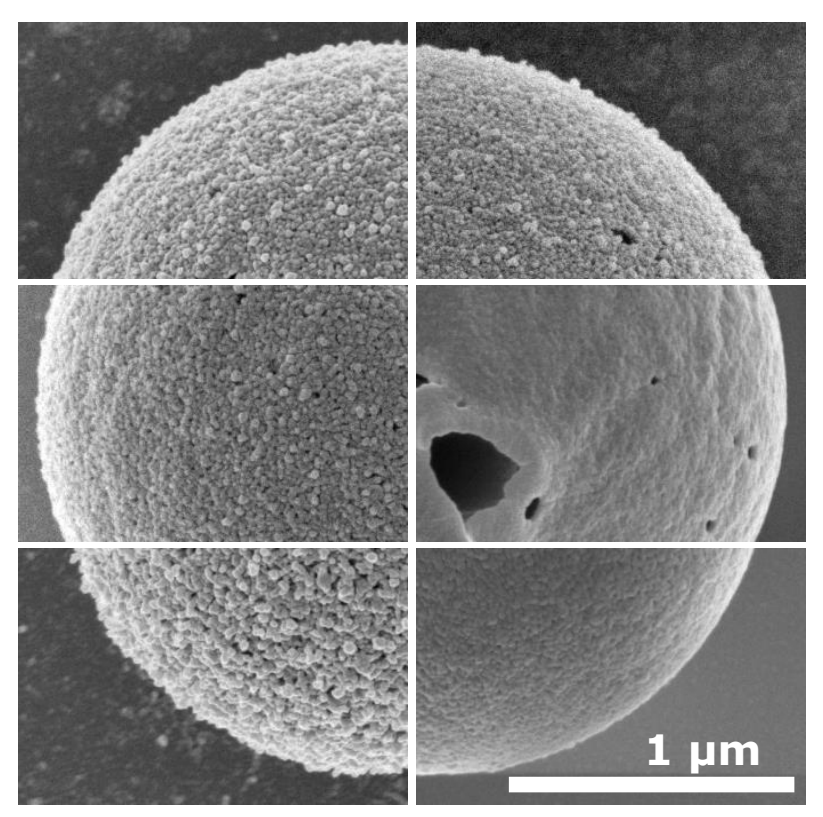

522

523 Figure 1: SEM images of sections of protein microbeads. Left-hand side, up-down: 25\%, $52420 \%, 15 \%$ heat-set. Right-hand side, up-down: rapidly heated 25\% heat-set, freeze-dried $25 \%$ 525 heat-set, $10 \%$ cold-set. 
Figure 2
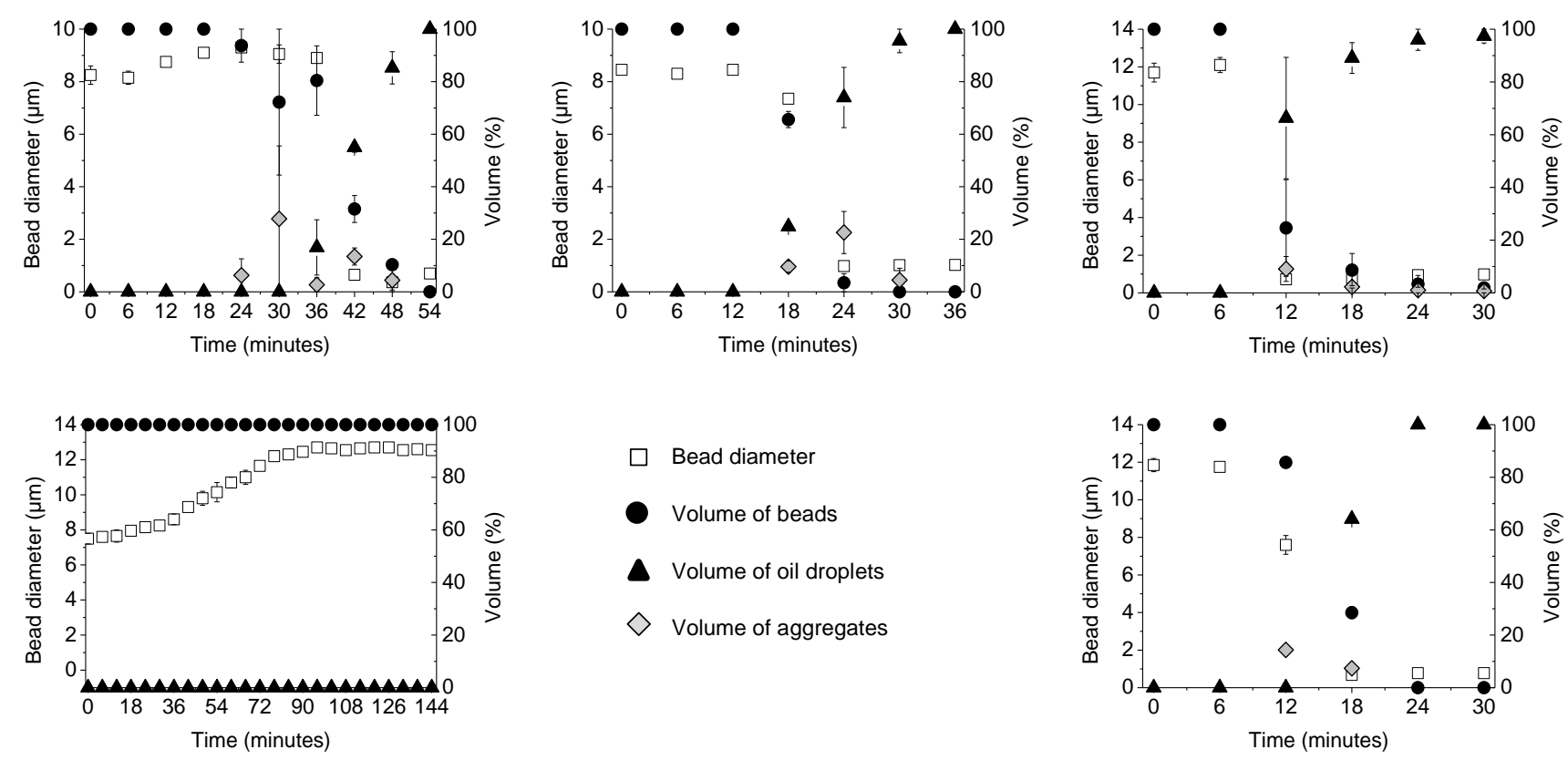

528

$\square \quad$ Bead diameter

Volume of beads

- Volume of oil droplets

$\diamond$ Volume of aggregates

529 Figure 2: Breakdown of WPI beads made with different WPI concentrations and process conditions. Top left to right: 25\%, 20\%, 15\% heat-set. Bottom left, right: rapidly heated 25\% heat-set, $10 \%$ cold-set. 
$532 \quad$ Figure 3

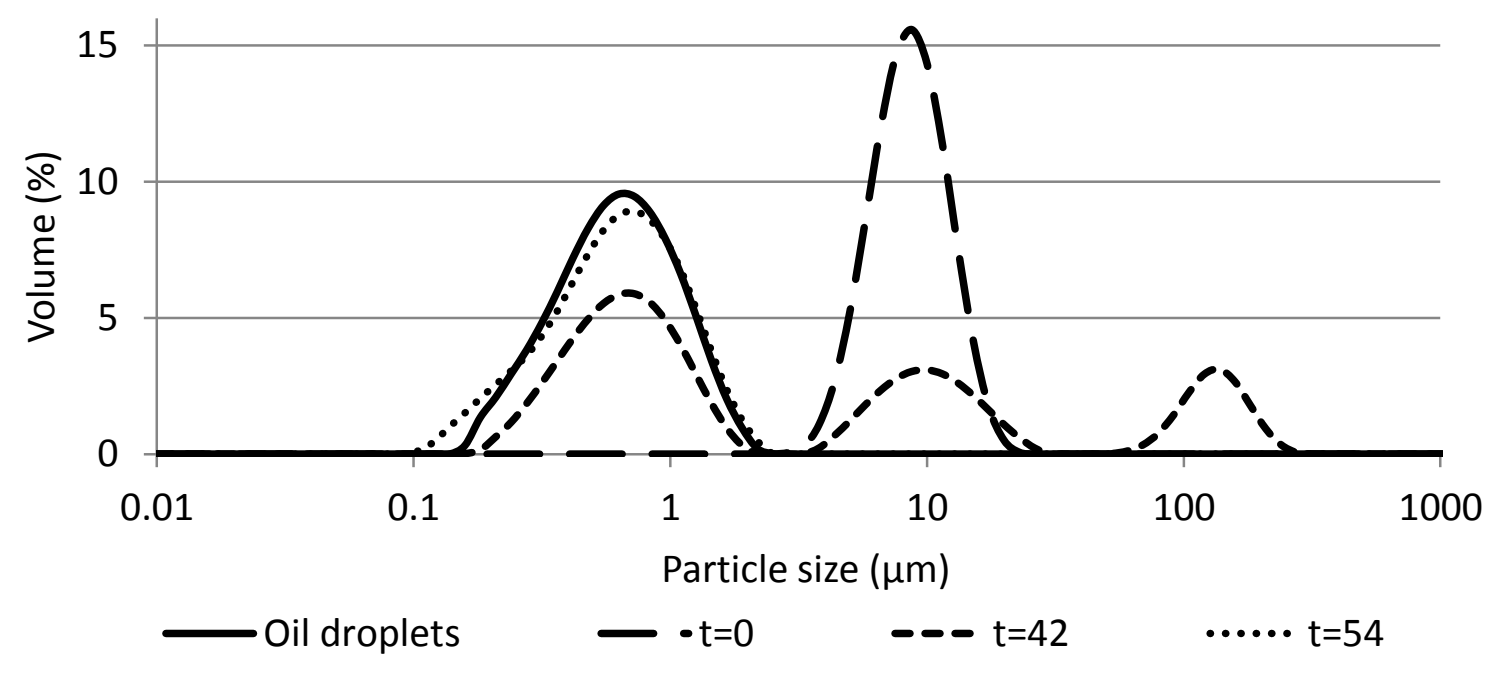

534 Size distribution graph during the breakdown of the $25 \%$ heat set beads, time is in minutes 

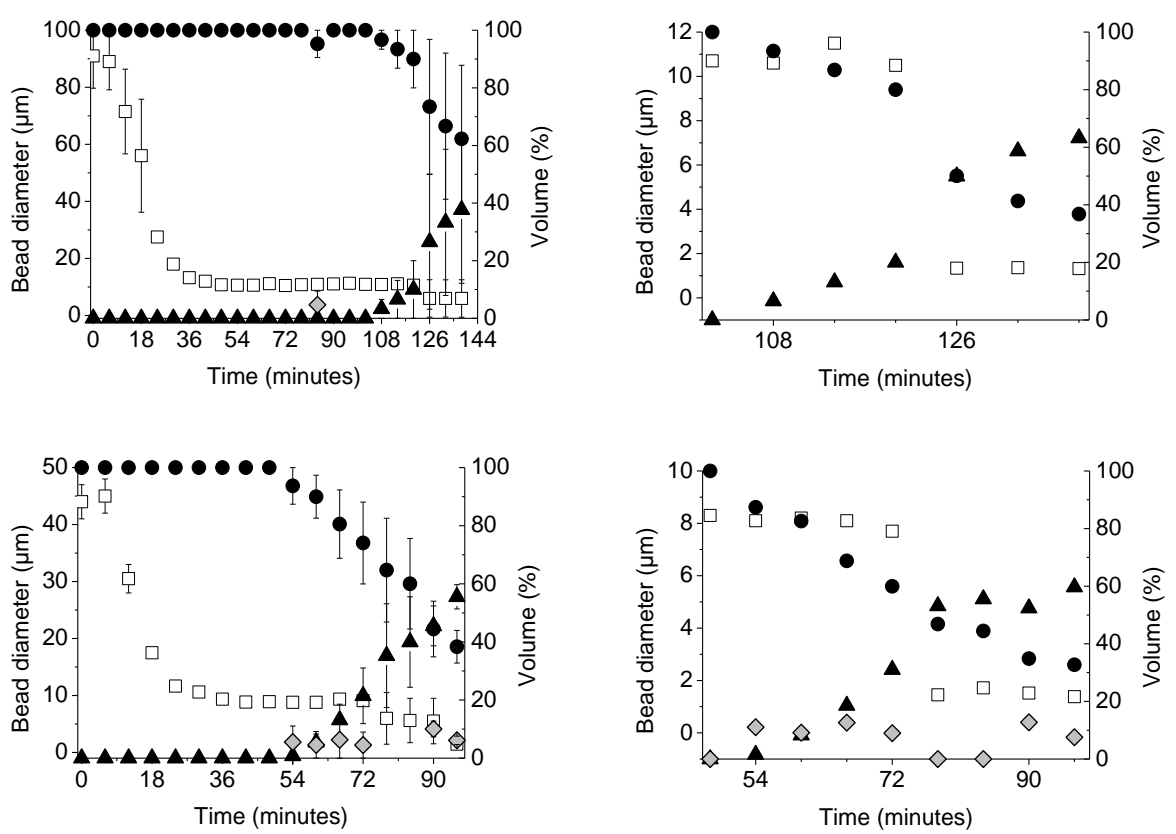

Bead diameter

- Volume of beads

A Volume of oil droplets Volume of aggregates

Figure 4: Breakdown of WPI beads. Top: left: freeze-dried beads, right: detail of a single measurement. Bottom: left: hydrated freeze-dried beads, right: detail of a single measurement. 
539 Figure 5

540
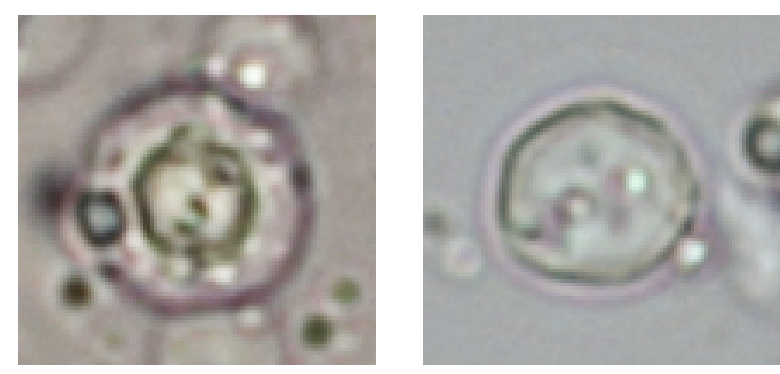

541 Figure 5: Microscopic observations of freeze-dried WPI beads during gastric treatment. Left:

542 after 60 minutes in SGF, Right: after overnight stirring in water. 
$543 \quad$ Figure 6
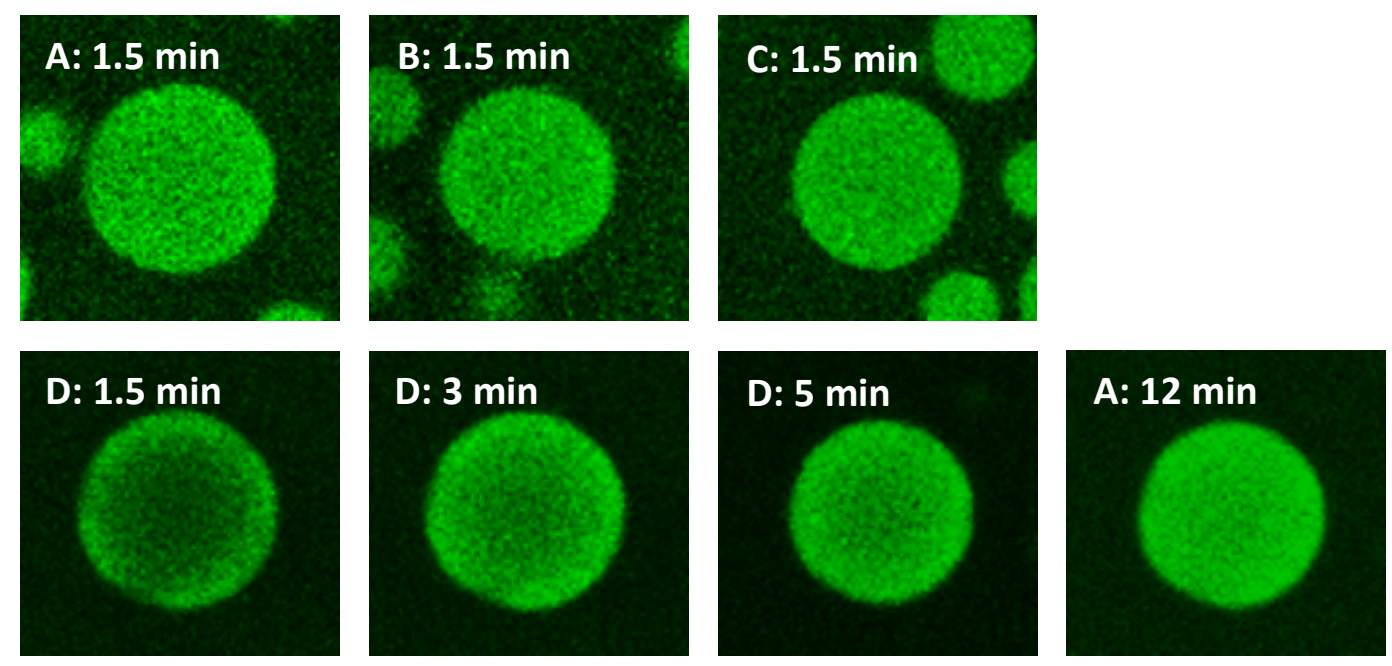

545 Figure 6: Diffusion of Dextran-FITC through 25\% heat-set (A), 25\% rapidly heated (B) 25\% 546 freeze-dried, hydrated (C) and 10\% cold-set (D) beads over time in minutes. 
547 Table 1: The expected amount and the measured amount of protein in the beads are given.

\begin{tabular}{l|ll} 
& Expected & Measured \\
& protein content & protein content \\
& $\%(\mathrm{w} / \mathrm{w})$ & $\%(\mathrm{w} / \mathrm{w})$ \\
\hline $25 \%$, heat-set & 82.46 & $81.02( \pm 0.36)$ \\
$20 \%$, heat-set & 79.00 & $77.45( \pm 0.36)$ \\
$15 \%$, heat-set & 73.83 & $70.70( \pm 0.08)$ \\
$10 \%$, cold-set & 65.29 & $55.95( \pm 0.10)$ \\
$25 \%$, quick heat-set & 82.46 & $79.98( \pm 0.19)$
\end{tabular}


549 Table 2: Summary of rate and way of breakdown of WPI beads with different protein

550 concentrations, gelation methods and further processing, in order of breakdown rate.

\begin{tabular}{|c|c|c|c|c|}
\hline $\begin{array}{l}\text { Bead type } \\
\text { (in order of } \\
\text { breakdown rate) }\end{array}$ & Microstructure & $\begin{array}{l}\text { Type of } \\
\text { breakdown }\end{array}$ & $\begin{array}{l}\text { Start release } \\
\text { (minutes) }\end{array}$ & $\begin{array}{l}\text { Complete } \\
\text { breakdown } \\
\text { (minutes) }\end{array}$ \\
\hline $\begin{array}{l}15 \% \text { protein } \\
\text { Heat-set }\end{array}$ & & $\begin{array}{l}\text { Reaction } \\
\text { limited }\end{array}$ & 6 & 18 \\
\hline $\begin{array}{l}10 \% \text { protein } \\
\text { External - Cold-set }\end{array}$ & & $\begin{array}{l}\text { Diffusion } \\
\text { limited }\end{array}$ & 6 & 18 \\
\hline $\begin{array}{l}20 \% \text { protein } \\
\text { Heat-set }\end{array}$ & & $\begin{array}{l}\text { Reaction } \\
\text { limited }\end{array}$ & 12 & 24 \\
\hline $\begin{array}{l}25 \% \text { protein } \\
\text { Heat-set }\end{array}$ & & $\begin{array}{l}\text { Reaction } \\
\text { limited }\end{array}$ & 18 & 48 \\
\hline $\begin{array}{l}25 \% \text { protein } \\
\text { Freeze-dried } \\
\text { Hydrated }\end{array}$ & & $\begin{array}{l}\text { Reaction } \\
\text { limited }\end{array}$ & 54 & $>90^{\mathrm{a}}$ \\
\hline & \multicolumn{4}{|c|}{2 hours: average residence time of food in the stomach } \\
\hline $\begin{array}{l}25 \% \text { protein } \\
\text { Freeze-dried }\end{array}$ & & $\begin{array}{l}\text { Reaction } \\
\text { limited }\end{array}$ & 120 & $>132^{\mathrm{b}}$ \\
\hline $\begin{array}{l}25 \% \text { protein } \\
\text { Heat-set - Fast heat }\end{array}$ & & $\begin{array}{l}\text { No } \\
\text { breakdown, }\end{array}$ & $>148$ & $>148^{c}$ \\
\hline increase & & $\begin{array}{l}\text { some } \\
\text { swelling }\end{array}$ & & \\
\hline
\end{tabular}


a: about $60 \%$ of the volume at the time mentioned is released oil droplets b: about $60 \%$ of the volume at the time mentioned is released oil droplets c: about $0 \%$ of the volume at the time mentioned is released oil droplets 